Pacific Journal of Mathematic 


\title{
ON NETS OF CONTRACTIVE MAPS IN UNIFORM SPACES
}

\author{
G. L. ITZKowitz
}

R. B. Fraser and $S$. Nadler have recently proved the following theorem: If $X$ is a locally compact metric space, if $f_{n} \rightarrow f_{0}$ pointwise, where each $f_{n}, n=0,1,2, \cdots$ is a contractive map with fixed point $a_{n}$, then $f_{n} \rightarrow f_{0}$ uniformly on compacta, and $a_{n} \rightarrow a_{0}$. Their method of proof actually showed more. In fact it implied that if $a_{0}$ was a fixed point of $f_{0}$, and if $U$ is a compact neighborhood of $a_{0}$, then there exists a natural number $N(U)$ such that if $n \geqq N(U)$ then $f_{n}$ had a fixed point $a_{n} \in U$, and $a_{n} \rightarrow a_{0}$. In 1963, W. J. Kammerer and R. H. Kasriel proved a theorem giving conditions for existence and uniqueness of fixed points of a general type contractive map on a uniform space. Edelstein in 1965, was able to considerably strengthen their results and achieved a significant extension of the Banach fixed point theorem. In this naper we show that the theorem of Fraser and Nadler may be extended with minor alteration to include locally compact uniform spaces. It was evident in the context of uniform spaces that the covergent sequences of their theorem should be replaced by covergent nets. Our method of proof is similar to their proof and used Edelstein's fixed point theorem.

1. Some preliminary results. In what follows let $(X, \mathfrak{u})$ be a uniform space and let $f$ be a mapping of $X$ into itself. Let $\mathfrak{B}$ be a symmetric base for the uniformity $\mathfrak{H}$.

Definition A. $f$ is said to be a $\mathfrak{B}$-contraction if for each $U \in \mathfrak{B}$ and $(x, y) \in U, x \neq y$, a $W \in \mathfrak{B}$ exists such that $(f(x), f(y)) \in W \subset$ int $U$, and $(x, y) \notin W$.

Definition B. $f$ is said to be $\mathfrak{B}$-contractive if for each $U \in \mathfrak{B}$ and $(x, y) \in U, x \neq y$, a $W \in \mathfrak{B}$ exists such that $(f(x), f(y)) \in W \subset U$ and $(x, y) \notin W$.

Definition C. $\mathfrak{B}$ is said to be ample if whenever $(x, y) \in U \in \mathfrak{B}$ there is $V \in \mathfrak{B}$ such that $(x, y) \in V \subset \bar{V} \subset U$.

REMARK. Except for minor changes the above terminology agrees with that used in the papers of Rhodes [8], Brown and Comfort [1], Kamerer and Kasriel [5], Edelstein [3], and Knill [7]. In addition, throughout we will use notation as standard in Kelley [6]. 
Notation. If $\mathfrak{B}$ is a base for the uniformity $\mathfrak{u}$ we will write $\overline{\mathfrak{B}}=\{\bar{B}: B \in \mathfrak{B}\}$. Note that if $\mathfrak{B}$ is ample then $\overline{\mathfrak{B}}$ is a base.

LEMma 1.1. Let $\mathfrak{B}$ be an ample base for $\mathfrak{U}$, let $f$ be a $\overline{\mathfrak{B}}$-contraction, and let $a_{0} \in X$, be such that $\bar{U}\left[a_{0}\right]$ is compact for some $U \in \mathfrak{B}$. Then there is $V \in \mathfrak{U}$ such that

$$
\bar{V}\left[f\left(a_{0}\right)\right] \subset \operatorname{int} U\left[f\left(a_{0}\right)\right]
$$

and $f(x) \in \bar{V}\left[f\left(a_{0}\right)\right]$ if $x \in \bar{U}\left[a_{0}\right]$.

Proof. Let $x \in \bar{U}\left[a_{0}\right]$ be arbitrary. Then there is $W_{x} \subset \operatorname{int} U$, $W_{x} \in \mathfrak{B}$, such that $f(x) \in \operatorname{int} W_{x}\left[f\left(a_{0}\right)\right]$. Since the map $g:\left(a_{0}, x\right) \mapsto f(x)$ is continuous and $\mathfrak{B}$ is ample, there is $U_{x} \subset \bar{U}_{x} \subset W_{x}, U_{x} \in \mathfrak{B}$, and $V_{x} \in \mathfrak{U}$, such that $x \in V_{x}\left[a_{0}\right], \quad f^{\prime}(x) \in U_{x}\left[f\left(a_{0}\right)\right]$ and if $y \in V_{x}\left[a_{0}\right]$ then $f(y) \in U_{x}\left[f\left(a_{0}\right)\right]$. Observe that the neighborhoods $\left\{V_{x}\left[a_{0}\right]: x \in \bar{U}\left[a_{0}\right]\right\}$ are an open cover of $\bar{U}\left[a_{0}\right]$ and so there is a finite subcover $V_{1}\left[a_{0}\right], \cdots$, $V_{k}\left[a_{0}\right]$ of $\bar{U}\left[a_{0}\right]$. Furthermore,

$$
\begin{aligned}
f\left(\bar{U}\left[a_{0}\right]\right) & \subset \bigcup_{i=1}^{k} f\left(V_{i}\left[a_{0}\right]\right) \subset \bigcup_{i=1}^{k} U_{i}\left[f\left(a_{0}\right)\right] \\
& \subset \bigcup_{i=1}^{k} \bar{U}_{i}\left[f\left(a_{0}\right)\right] \subset \bigcup_{i=1}^{k} W_{i}\left[f\left(a_{0}\right)\right] \subset \operatorname{int} U\left[f\left(a_{0}\right)\right] .
\end{aligned}
$$

Since $V=\bigcup_{i=1}^{n} U_{i}$ satisfies $V \in \mathfrak{H}$,

$$
\bar{V}\left[f\left(a_{0}\right)\right]=\bigcup_{i=1}^{k} U_{i}\left[f\left(a_{0}\right)\right] \subset \operatorname{int} U\left[f\left(a_{0}\right)\right]
$$

and

$$
f(x) \in \bar{V}\left[f\left(a_{0}\right)\right], \text { if } x \in \bar{U}\left[a_{0}\right],
$$

the lemma is proved.

REMARK. It should be noted that the proof went through by means of a standard compactness argument because a contraction $f$ maps a point of $\bar{U}\left[a_{0}\right]$ into the interior of $\bar{U}\left[f\left(a_{0}\right)\right]$. Thus any contractive map $g$ on $\bar{U}\left[a_{0}\right]$ that sends $x \in \bar{U}\left[a_{0}\right]$ into int $\bar{U}\left[g\left(a_{0}\right)\right]$, for each $x \in \bar{U}\left[a_{0}\right]$, could be substituted for $f$ in the lemma. We shall be applying this fact in the future in the special case where $g\left(a_{0}\right)=a_{0}$.

DEFINITION D. A uniform space $(X, \mathfrak{u})$ is $U$-chainable, if for each pair $x, y \in X$, a finite sequence $x=x_{0}, x_{1}, \cdots, x_{n}=y$ exists such that $\left(x_{i-1}, x_{i}\right) \in U \in \mathfrak{U}$ for $i=1,2, \cdots, n$. Such a sequence is called a $U$-chain. 
CoROLlary 1.2. If $U \in \mathfrak{U}$ is symmetric then $\bar{U}[x]$ is $U$-chainable, for each $x \in X$.

Proof. If $y, r \in \bar{U}[x]$, there is $z \in U[y] \cap U[x]$ and $s \in U[r] \cap U[x]$, so that $(y, z) \in U,(z, x) \in U,(x, s) \in U$, and $(s, r) \in U$.

Definition E. Let $\xi \in X$ then $X^{f}(\xi)=\{y: y$ is a cluster point of the sequence $\left.\left\{f^{n}(\xi)\right\}_{n=1}^{\infty}\right\}$. Here $f^{n}[x]=f\left(f^{n-1}(x)\right)$.

Theorem 1.3. (M. Edelstein [3]). Let $\mathfrak{B}$ be an open ample base for $(X, \mathfrak{i})$, a $U$-chainable uniform space for some $U \in \mathfrak{B}$, and let $f: X \rightarrow X$ be B-contractive. If $X^{f}(\xi) \neq \varnothing$, for some $\xi$, if $x \in X^{f}(\xi)$, and if $X^{f}(y) \neq \varnothing$ for each $y \in U[x]$, then $f$ has the unique fixed point $x$.

REMARK. The theorem above is a slightly weaker form of the theorem of M. Edelstein. The condition $X^{f}(\xi) \neq \varnothing$, for some $\xi$ is needed in the theorem as may be seen by the following example.

Let $G=R \times Z$ where $R$ denotes the real line with the usual topology, and $Z$ denotes the integers with the discrete topology. This $G$ is locally compact, $\sigma$-compact, locally connected, and even metrizable. Let $f: G \rightarrow G$ be defined by $f(x, k)=\left(\frac{1}{2} x, k+1\right)$. Then $f$ is a contraction on the base $\mathfrak{B}=\left\{U^{*}:(\xi, y) \in U^{*}\right.$ if and only if $y \in \xi(U \times\{0\})$, where $U$ is a basic open neighborhood of $0 \in R\}$. However $X^{f}(\xi)=\varnothing$ for every $\xi \in G$, and clearly $f$ has no fixed point.

We note that W. J. Krammerer and R. K. Kasriel [5] proved a slightly weaker form of 1.3. They showed that if $\mathfrak{B}$ is an ample base for $(X, \mathfrak{u})$, a $U$-chainable uniform space $(U \in \mathfrak{B})$, and if some iterate of $X$ under $f$ is compact, where $f$ is $\mathfrak{B}$-contractive, then $f$ has a unique fixed point.

CoRollary 1.4. Let $\mathfrak{B}$ be an ample open base of the uniformly locally compact uniform space $(X, \mathfrak{u})$. Let $U \in \mathfrak{B}$ be such that $\bar{U}[x]$ is compact for all $x \in X$. Suppose that

(i) $f$ is $\mathfrak{B}$-contractive

(ii) there exists an $x \in X$ such that $f$ maps $U[x]$ into itself.

Then the following occur

(i) $f$ has exactly one fixed point $y$ in $\bar{U}[x]$.

(ii) the filter base $f^{n}[\bar{U}[x]]$ converges to $y$

(iii) for each $\bar{V} \subset \bar{B}$ there exists $k$ such that $f^{k}(\bar{U}[x]) \subset$ int $\bar{V}\left[f^{k}(x)\right]$. Furthermore, if $X$ is $U$-chainable, then $f$ has a unique fixed point.

Proof. We may observe that $f$ is continuous so that $f(\bar{U}[x]) \subset$ $\bar{U}[x]$. Also $\bar{U}$ is $U$-chainable by 1.2. Let $G$ be the restriction of $f$ 
to $\bar{U}[x]$. Then $g: \bar{U}[x] \rightarrow \bar{U}[x]$ and $\bar{U}[x]$ is compact. Thus $g$ and $\bar{U}$ satisfy the conditions of the theorem of Kamerer and Kasriel so that $\bar{U}[x]$ has exactly one fixed point of $g$, say $y$. This proves (i).

According to the theorem of Kammerer and Kasriel [5], $\{y\}=$ $\bigcup\left\{X^{g}(\xi): \xi \in \bar{U}[x]\right\}$. Let now $z \in \bar{U}[x]$, and let $V \in \mathfrak{B}$. Since $f^{n}(z) \rightarrow y$ there is an integer $N(z)$ such that $n \geqq N(z)$ implies that $f^{n}(z) \in V[y]$. Since $f$ is continuous there is $W_{z} \in \mathfrak{B}$ such that $f^{n}\left(W_{z}[z]\right) \subset V[y]$. Clearly the collection $\left\{W_{z}[z]: z \in \bar{U}[x]\right\}$ covers $\bar{U}[x]$ and so a finite subcollection $W_{1}\left[z_{1}\right], \cdots, W_{k}\left[z_{k}\right]$ also covers $\bar{U}[x]$. But then if $n \geqq$ $N\left(z_{1}\right)+\cdots+N\left(z_{k}\right)$, it follows that $f^{n}(\bar{U}[x]) \subset V[y]$, proving (ii).

Let $V \in \mathfrak{B}$ and let $W \in \mathfrak{B}$ be such that $W \circ W \subset$ int $\bar{V}$, and $W \subset V$. By part (ii) there is $k$ such that

$$
f^{k}(\bar{U}[x]) \subset W[y] \text {. }
$$

Let $z \in \bar{U}[x]$, then

$$
\left(f^{k}(z), y\right) \in W \text { and }\left(y, f^{k}(x)\right) \in W
$$

so that $f^{k}(z) \in W \circ W\left[f^{k}(x)\right] \subset \operatorname{int} \bar{V}\left[f^{k}(x)\right]$. But then

$$
f^{k}(\bar{U}[x]) \subset \operatorname{int} \bar{V}\left[f^{k}(x)\right]
$$

proving (iii).

The final statement of this corollary is evident from Edelstein's theorem.

REMARK. Condition (ii) was suggested by theorem due to Knill [7]; p. 453.

2. The main results. The above theorem of M. Edelstein and the resultant corollary allows us to choose the setting for a generalization of the theorem of R. B. Fraser and S. Nadler [4] on contractive maps with fixed points. It is evident that in a uniform space where sequential convergence does not suffice to describe topological properties it is natural to replace sequential convergence of functions by convergence of nets of functions. Thus we use the following.

Theorem 2.1. Let $(X, \mathfrak{u})$ be uniformly locally compact and let $\mathfrak{B}$ be an ample base. If $\left\{f_{\alpha}: \alpha \in D\right\}$ is a net of $\mathfrak{B}$-contractive maps, of $X$ into itself, converging pointwise to $f_{0}$, a $\mathfrak{B}$-contractive map, then $f_{\alpha}$ converges uniformly to $f_{0}$ on each compact set $K \subset G$.

Proof. Let $U \in \mathfrak{B}$ be arbitrary, and let $V \in \mathfrak{B}$ be such that $V \circ V \circ V \subset U, V \subset U$ (see Kelley [6], p. 180. Th. 8). Since $f_{\alpha} \rightarrow f_{0}$ pointwise there exists for each $x$, an $\alpha(x) \in D$, such that $\alpha \geqq \alpha(x)$ 
implies that $\left(f_{0}(x), f_{\alpha}(x)\right) \in V$.

Clearly if $K$ is compact the collection $\{V[x]: x \in K\}$ is a cover of $K$ and hence is reducible to a finite subcover $V\left[x_{1}\right], \ldots, V\left[x_{k}\right]$ of $K$ (note that the collection $\{$ int $V[x]: x \in K\}$ is an open cover of $K$ ). For each $i$, let $\alpha_{i}=\alpha\left(x_{i}\right) \in D$, be such that $\left(f_{0}\left(x_{i}\right), f_{\alpha}\left(x_{i}\right)\right) \in V$ if $\alpha \geqq \alpha_{i}$.

Let $x \in K$ be arbitrary. Then there is $x_{j} \in\left\{x_{1}, \cdots, x_{k}\right\}$ such that $\left(x_{j}, x\right) \in V$ and therefore $\left(f_{\alpha}\left(x_{j}\right), f_{\alpha}(x)\right) \in V$ for all $\alpha$, since the $f_{\alpha}$ are B-contractive. Thus if $\alpha_{0} \geqq\left(\alpha_{1}, \cdots, \alpha_{n}\right)$ we have for all $\alpha \geqq \alpha_{0}$ that $\left(f_{0}(x), f_{\alpha}(x)\right) \in V \circ V \circ V \subset U$. [Since $\left(f_{0}(x), f_{0}\left(x_{j}\right)\right) \in V,\left(f_{0}\left(x_{j}\right), f_{\alpha}\left(x_{j}\right)\right) \in V$, and $\left.\left(f_{\alpha}\left(x_{j}\right), f_{\alpha}(x)\right) \in V.\right]$

REMARK. It is evident from the proof of 2.1 that the theorem is true if the $f_{\alpha}\left(f_{0}\right)$ are weakly contractive [5] or nonexpansive [3].

THEOREM 2.2. Let $\mathfrak{B}$ be an ample open base of the uniformly locally compact uniform space $(X, \mathfrak{u})$. Let $U \in \mathfrak{B}$ be such that $\bar{U}[x]$ is compact for all $x \in X$. Let $\left\{f_{\alpha}: X \rightarrow X \mid \alpha \in D\right\}$ be a net of $\overline{\mathfrak{B}}$ contractions, and let $f_{\alpha} \rightarrow f$ pointwise, where $f$ is a $\bar{B}$-contraction. If $f$ has a fixed point $y_{0}$, then

(i) there is $\alpha_{0} \in D$ such that if $\alpha \geqq \alpha_{0}$ then $f_{a}$ has exactly one fixed point in $\bar{U}\left[y_{0}\right]$, say $y_{\alpha}$.

(ii) $y_{\alpha} \rightarrow y_{0}$.

Furthermore if $X$ is $U$-chainable then $y$ is a unique fixed point of $f$ and $y_{\alpha}, \alpha \geqq \alpha_{0}$, are unique fixed points of $f_{\alpha}$.

Proof. We observe that $\bar{U}\left[y_{0}\right]$ is a compact neighborhood of $y_{0}$. Since $f$ is a $\overline{\mathfrak{B}}$-contraction there is $V \in \mathfrak{U}$ such that $\bar{V}\left[y_{0}\right] \subset U\left[y_{0}\right]$ and $f(x) \in \bar{V}\left[y_{0}\right]$ if $x \in \bar{U}\left[y_{0}\right]$ (1.1). By Theorem 33 in Kelley [6], there is $W \in \mathfrak{U}$ such that $W\left[\bar{V}\left[y_{0}\right]\right] \subset U\left[y_{0}\right]$.

By Theorem 2.1, $f_{\alpha} \rightarrow f$ uniformly on $U\left[y_{0}\right]$, and so there is $\alpha_{0}$ such that $\alpha \geqq \alpha_{0}$ implies that $f_{\alpha}(x) \in W[f(x)]$ for all $x \in U\left[y_{0}\right]$. But then if $x \in U\left[y_{0}\right]$, and $\alpha \geqq \alpha_{0}$ we have

$$
f_{\alpha}(x) \in W \circ \bar{V}\left[y_{0}\right] \subset U\left[y_{0}\right]
$$

since $f(x) \in \bar{V}\left[y_{0}\right]$ and $f_{\alpha}(x) \in W[f(x)]$. This shows that $f_{\alpha}, \alpha \geqq \alpha_{0}$ maps $U\left[y_{0}\right]$ into itself. By Corollary 1.4, $\bar{U}\left[y_{0}\right]$ contains exactly one fixed point of $f_{\alpha}$, if $\alpha \geqq \alpha_{0}$, proving (i).

Since we could repeat the above argument for each $V \in \mathfrak{B}$, $V \subset U$, it follows that $y_{\alpha} \rightarrow y_{0}$, proving (ii). The remainder of the proof is clear.

REMARK. The index $\alpha_{0}$ above depends on $W$ which in turn depends on $U$. This is the reason we may conclude $y_{\alpha} \rightarrow y_{0}$. Further- 
more a straightforward application of 1.4 yields the fact that the fixed point $y_{\alpha}$ is an isolated fixed point of $f_{\alpha}$.

THEOREM 2.3. Let $\mathfrak{B}$ be an ample open base of the uniformly locally compact uniform space $(X, \mathfrak{u})$. Let $U \in \mathfrak{B}$ be such that $\bar{U}[x]$ is compact for all $x \in X$, and suppose $X$ is U-chainable. Let $\left\{f_{\alpha}: X \rightarrow X \mid \alpha \in D\right\}$ be a net of $\mathfrak{B}$-contractive maps, and let $f_{\alpha} \rightarrow f$ pointwise, where $f$ is a $\mathfrak{B}$-contractive map.

If $f$ has fixed point $y_{0}$, then

(i) there is $\alpha_{0} \in D$ such that if $\alpha \geqq \alpha_{0}$ then $f_{\alpha}$ has exactly one fixed point $y_{\alpha} \in X$

(ii) $y_{\alpha} \rightarrow y_{0}$.

Proof. We observe that since $f$ is $\mathfrak{B}$-contractive, there is by 1.4 and 1.1 an integer $k$ and a $V \in \mathfrak{U}$, such that $\bar{V}\left[y_{0}\right] \subset U\left[y_{0}\right]$ and $f^{k}(x) \in V\left[y_{0}\right]$ if $x \in \bar{U}\left[y_{0}\right]$. By Theorem 33 in Kelley [6], there is $W \in \mathfrak{U}$ such that $W\left[\bar{V}\left[y_{0}\right]\right] \subset U\left[y_{0}\right]$.

By Theorem 2.1, (since $g^{k}$ is a $\mathfrak{B}$-contractive map if $g$ is) $f_{\alpha}^{k} \rightarrow f^{k}$ uniformly on $\bar{U}\left[y_{0}\right]$, and so there is $\alpha_{0}$ such that $\alpha \geqq \alpha_{0}$ implies that $f_{\alpha}^{k}(x) \in W\left[f^{k}(x)\right]$ for all $x \in \bar{U}\left[y_{0}\right]$. But then if $x \in U\left[y_{0}\right]$, and $\alpha \geqq \alpha_{0}$ we have

$$
f_{\alpha}^{k}(x) \in W\left[\bar{V}\left[y_{0}\right]\right] \subset U\left[y_{0}\right]
$$

since $f^{k}(x) \in \bar{V}\left[y_{0}\right]$ and $f_{\alpha}^{k}(x) \in W[f(x)]$. This shows that $f_{\alpha}^{k}, \alpha \geqq \alpha_{0}$ maps $U\left[y_{0}\right]$ into itself. For each $j=1, \cdots, k-1$, let $n_{j}$ be the smallest integer such that $f_{\alpha}^{j}\left(y_{0}\right) \in U^{n_{j}}\left[y_{0}\right]$. Let $f_{\alpha}^{0}=i d$, and $Y_{\alpha}=$ $\bigcup_{j=0}^{k-1} \bar{U}^{n}\left[f_{\alpha}^{j}\left(y_{0}\right)\right]$, where $n=\sup \left\{n_{1}, \cdots, n_{k-1}\right\}$. Then $Y_{\alpha}$ is compact (each $\bar{U}^{n_{j}}[x]=\bar{U} \circ \bar{U}^{n_{j}-1}[x]$ is compact for all $x \in X$ ), and $U$-chainable, and $f_{\alpha}: Y_{\alpha} \rightarrow Y_{\alpha}$. Thus the theorem of Kammerer and Kasriel [5] implies that $f_{\alpha}$ has a unique fixed point in $Y_{\alpha}$. But then by 1.3 and the fact that $X^{f_{\alpha}}(\xi) \cap \bar{U}\left[y_{0}\right] \neq \varnothing$ for $\xi \in \bar{U}\left[y_{0}\right]$ (Since $f_{\alpha}^{k}: \bar{U}\left[y_{0}\right] \rightarrow \bar{U}\left[y_{0}\right]$ ) it follows that $\bar{U}\left[y_{0}\right]$ contains the fixed point $y_{\alpha}$. The remainder of the proof follows as in 2.2 .

\section{BIBLIOGRAPHY}

1. T. A. Brown and W. W. Comfort, New methods for expansion and contraction maps in uniform spaces, Proc. Amer. Math. Soc. 11 (1960), 483-486.

2. Michael Edelstein, On fixed and periodic points under contractive mappings, J. London Math. Soc. 37 (1962), 74-79.

3. - On nonexpansive mappings of uniform spaces, Nederl. Akad. Wetensch. Proc. 68 (Indag. Math. 27) (1965), 47-51.

4. R. B. Fraser, Jr. and S. B. Nadler, Jr., Sequences of contractive maps and fixed points (to appear in Pacific J. Math.)

5. W. J. Kammerer and R. H. Kasriel, On contractive mappings in uniform spaces, 
Proc. Amer. Math. Soc. 15 (1964), 288-290.

6. John L. Kelley, General Topology, Van Nostrand, New York 1955.

7. R. J. Knill, Fixed points of uniform contractions, J. Math. Anal. and Appl. 12 (1965), 449-455.

8. F. Rhodes, A generalization of isometries to uniform spaces, Proc. Cambridge Philos. Soc. 52 (1956), 399-405.

Received November 21, 1969, and in revised form February 12, 1970.

State University of New York at Buffalo 



\section{PACIFIC JOURNAL OF MATHEMATICS}

\section{EDITORS}

\author{
H. SAMELSON \\ Stanford University \\ Stanford, California 94305

\section{Richard Pierce} \\ University of Washington \\ Seattle, Washington 98105
}

J. DugundJI

Department of Mathematics

University of Southern California

Los Angeles, California 90007

RichaRd ARENS

University of California

Los Angeles, California 90024

\section{ASSOCIATE EDITORS}
E. F. BECKENBACH
B. H. NeUMANN
F. WOLE
K. YoshidA

\section{SUPPORTING INSTITUTIONS}

\author{
UNIVERSITY OF BRITISH COLUMBIA \\ CALIFORNIA INSTITUTE OF TECHNOLOGY \\ UNIVERSITY OF CALIFORNIA \\ MONTANA STATE UNIVERSITY \\ UNIVERSITY OF NEVADA \\ NEW MEXICO STATE UNIVERSITY \\ OREGON STATE UNIVERSITY \\ UNIVERSITY OF OREGON \\ OSAKA UNIVERSITY \\ UNIVERSITY OF SOUTHERN CALIFORNIA
}

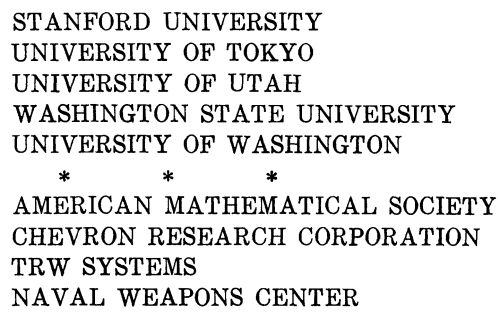

The Supporting Institutions listed above contribute to the cost of publication of this Journal, but they are not owners or publishers and have no responsibility for its content or policies.

Mathematical papers intended for publication in the Pacific Journal of Mathematics should be in typed form or offset-reproduced, (not dittoed), double spaced with large margins. Underline Greek letters in red, German in green, and script in blue. The first paragraph or two must be capable of being used separately as a synopsis of the entire paper. The editorial "we" must not be used in the synopsis, and items of the bibliography should not be cited there unless absolutely necessary, in which case they must be identified by author and Journal, rather than by item number. Manuscripts, in duplicate if possible, may be sent to any one of the four editors. Please classify according to the scheme of Math. Rev. Index to Vol. 39. All other communications to the editors should be addressed to the managing editor, Richard Arens, University of California, Los Angeles, California, 90024.

50 reprints are provided free for each article; additional copies may be obtained at cost in multiples of 50 .

The Pacific Journal of Mathematics is published monthly. Effective with Volume 16 the price per volume (3 numbers) is $\$ 8.00$; single issues, $\$ 3.00$. Special price for current issues to individual faculty members of supporting institutions and to individual members of the American Mathematical Society: $\$ 4.00$ per volume; single issues $\$ 1.50$. Back numbers are available.

Subscriptions, orders for back numbers, and changes of address should be sent to Pacific Journal of Mathematics, 103 Highland Boulevard, Berkeley, California, 94708.

PUBLISHED BY PACIFIC JOURNAL OF MATHEMATICS, A NON-PROFIT CORPORATION

Printed at Kokusai Bunken Insatsusha (International Academic Printing Co., Ltd.), 7-17, Fuj̣imi 2-chome, Chiyoda-ku, Tokyo, Japan. 


\section{Pacific Journal of Mathematics}

\section{Vol. 35, No. $2 \quad$ October, 1970}

Valentin Danilovich Belousov and Palaniappan L. Kannappan, Generalized Bol functional equation .................................... 259

Charles Morgan Biles, Gelfand and Wallman-type compactifications ........... 267

Louis Harvey Blake, A generalization of martingales and two consequent convergence theorems .................................... 279

Dennis K. Burke, On p-spaces and $w \Delta$-spaces..................... 285

John Ben Butler, Jr., Almost smooth perturbations of self-adjoint operators . . . . . . 297

Michael James Cambern, Isomorphisms of $C_{0}(Y)$ onto $C(X) \ldots \ldots \ldots \ldots \ldots . \ldots 307$

David Edwin Cook, A conditionally compact point set with noncompact closure ... 313

Timothy Edwin Cramer, Countable Boolean algebras as subalgebras and homomorphs .........................................

John R. Edwards and Stanley G. Wayment, A v-integral representation for linear operators on spaces of continuous functions with values in topological vector spaces.............................................

Mary Rodriguez Embry, Similarities involving normal operators on Hilbert

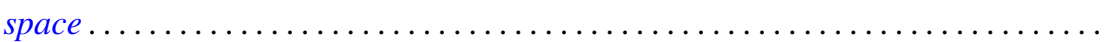

Lynn Harry Erbe, Oscillation theorems for second order linear differential

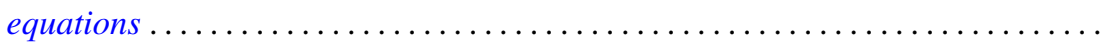

William James Firey, Local behaviour of area functions of convex bodies .......... Joe Wayne Fisher, The primary decomposition theory for modules ..............

Gerald Seymour Garfinkel, Generic splitting algebras for Pic ..................

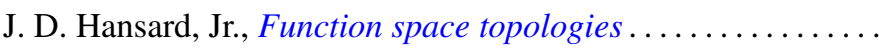

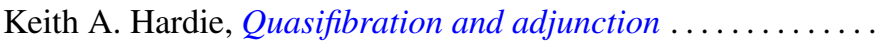

G. Hochschild, Coverings of pro-affine algebraic groups ...........

Gerald L. Itzkowitz, On nets of contractive maps in uniform spaces ..

381

389

399

417

Melven Robert Krom and Myren Laurance Krom, Groups with free nonabelian subgroups....................................

James Robert Kuttler, Upper and lower bounds for eigenvalues by finite differences ......................................

Dany Leviatan, A new approach to representation theory for convolution transforms . . .

Richard Beech Mansfield, Perfect subsets of definable sets of real numbers ...

Brenda MacGibbon, A necessary and sufficient condition for the embedding of a

Lindelof space in a Hausdorff $\mathscr{H} \sigma$ space ..................

David G. Mead and B. D. McLemore, Ritt's question on the Wronskian ....

Edward Yoshio Mikami, Focal points in a control problem .....

Paul G. Miller, Characterizing the distributions of three independent n-dimensional random variables, $X_{1}, X_{2}, X_{3}$, having analytic characteristic functions by the joint distribution of $\left(X_{1}+X_{3}, X_{2}+X_{3}\right)$. . .

P. Rosenthal, On the Bergman integral operator for an elliptic partial differential equation with a singular coefficient....

Douglas B. Smith, On the number of finitely generated $O$-group 